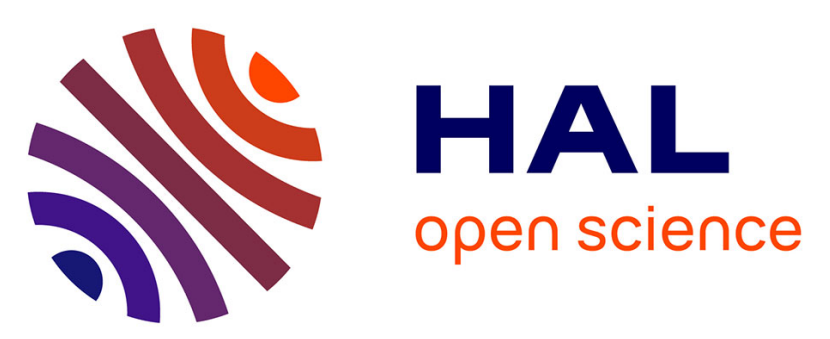

\title{
Femoral malrotation from diaphyseal fractures results in changes in patellofemoral alignment and in higher patellofemoral stress from a finite element model study
}

Louis Dagneaux, Raphael Allal, Martine Pithioux, Patrick Chabrand, Matthieu Ollivier, Jean-Noël Argenson

\section{To cite this version:}

Louis Dagneaux, Raphael Allal, Martine Pithioux, Patrick Chabrand, Matthieu Ollivier, et al.. Femoral malrotation from diaphyseal fractures results in changes in patellofemoral alignment and in higher patellofemoral stress from a finite element model study. The Knee, 2018, 25 (5), pp.807-813. 10.1016/j.knee.2018.06.008 . hal-01960537

\section{HAL Id: hal-01960537 https://hal.science/hal-01960537}

Submitted on 19 Apr 2019

HAL is a multi-disciplinary open access archive for the deposit and dissemination of scientific research documents, whether they are published or not. The documents may come from teaching and research institutions in France or abroad, or from public or private research centers.
L'archive ouverte pluridisciplinaire HAL, est destinée au dépôt et à la diffusion de documents scientifiques de niveau recherche, publiés ou non, émanant des établissements d'enseignement et de recherche français ou étrangers, des laboratoires publics ou privés. 
1 TITLE: Femoral malrotation from diaphyseal fractures results in changes in

2 patellofemoral alignment and in higher patellofemoral stress from a Finite

3 element model study.

4

5 Authors names and affiliations:

6 Louis DAGNEAUX MD MSc ${ }^{1,2}$, Raphael ALLAL MD MSc ${ }^{1}$, Martine PITHIOUX PhD

7 ', Patrick CHABRAND PhD ${ }^{1}$, Matthieu OLLIVIER MD PhD ${ }^{1}$, Jean-Noël ARGENSON

$8 \mathrm{MD} \mathrm{PhD}^{1}$

9

$10{ }^{1}$ Aix Marseille Univ, APHM, CNRS, ISM, Sainte-Marguerite Hospital, Institute for

11 Locomotion, Department of Orthopaedics and Traumatology, Marseille, France

$12{ }^{2}$ Department of Orthopaedic Surgery, Lower limb surgery Unit, Lapeyronie University

13 Hospital, 351 av. Gaston Giraud, 34295 Montpellier cedex 05, France

14

corresponding author: Louis DAGNEAUX

16 address: Department of Orthopaedic Surgery, Lower limb surgery Unit, Lapeyronie

17 University Hospital, 351 av. Gaston Giraud, 34295 Montpellier cedex 05, France

18 email: louisdagneaux@gmail.com

19

20

21

22 


\section{ABSTRACT}

Introduction

26 Malrotation of the femur is a frequent complication in the management of diaphyseal fracture, often, 27 responsible for pain and adverse functional results. Among these complications, contact stresses effects 28 on patellofemoral joint are recognized as a predictive factor of impaired results. The purpose of this 29 study was to analyze the effect of malrotation on stress distribution on the patellofemoral joint, using 30 radiological measurement and three-dimensional finite element models.

\section{Material and methods}

32 Functional analysis of the patellofemoral joint was evaluated in 8 knees pairs from patient suffering from

33 unilateral femoral fracture and subsequent femoral malrotation. A CT-based protocol allowed 34 patellofemoral joint analysis, then a finite element model of the healthy (contralateral) knee was created 35 from 3D reconstruction at 30 degrees of flexion. In this FE model, incremental rotational malalignment 36 was simulated to observe changes in stress distribution on the patellar surface.

\section{Results}

38 Femoral malrotation was associated with anomalies in the rotational alignment of the patellofemoral 39 joint. Internal rotation resulted in increased stress on the lateral side of the patella. Comparatively, the 40 external rotation increased inferiorly medial side stress.

\section{Discussion}

42 Rotational disorders of the distal femur resulted in increased stress on the patellofemoral joint and 43 alignment changes. Malrotation in internal and external rotation might cause patellofemoral pain 44 syndrome from rotations smaller than ten degrees.

\section{Conclusions}

46 Care should be taken especially for internal malrotation in the management of femoral shaft fracture.

Level of Evidence: IV (Experimental study)

49 Keywords: femoral malrotation, patellofemoral joint, patellar stress, finite element model, patellofemoral alignment, biomechanics 


\section{INTRODUCTION}

52 Postoperative malunion of femoral shaft is a well-known and frequent complication of

53 diaphyseal fracture. Fracture of the femoral shaft is classically managed by antegrade

54 intramedullary nailing as the standard treatment. Good results are reported due to early 55 weight-bearing conditions and joint physiotherapy [1-6]. However femoral malrotation 56 of more than ten degrees ranges until $40 \%$ in clinical series [2,5]. Surgeons are 57 particularly overexposed to this challenge in case of polytrauma or gunshot wounds, 58 with $12.3 \%$ of patient's series with postoperative difference of femoral version greater 59 than 15 degrees [7].

60 The clinical behavior is usually well tolerated according to malrotation location, amount

61 and type of osteosynthesis used. Several reports deled with these functional 62 implications on the lower-limb. Gugala et al reported compensation in foot rotation after 63 healed diaphyseal femur fractures and emphasized inability to reliably determine 64 rotational femur discrepancy [2]. Major malrotation in healed femur results in poor 65 functional outcomes especially in young and active patient. Due to pain or kinematic trouble in the patellofemoral joint that affect functional results. Adversely, the relation between patellofemoral malalignment and femoral component malrotation is a wellknown effect on patellar biomechanics after total knee arthroplasty [8-10].

The aim of this study was to determine the role of femoral malrotation in the distribution of loading variations in the PF joint. We hypothesized that femur malrotation is

71 responsive for biomechanics changes in PF joint and would increase from small degrees of femur malrotation despite of clinical relevance. This study examines these changes by evaluating the patellar position and joint congruency in series of patients 74 with femoral malrotation more than $10^{\circ}$. We analyzed the patellar stress distribution 
75 from a finite element model (FEM) after simulating gradually malrotation in the femoral 76 shaft. 


\section{MATERIAL AND METHODS}

\subsection{Patient inclusion}

Between 2012 and 2015, consecutive patients with diaphyseal femur fractures were treated at our level 1 trauma center (University Hospital of Marseille, France). These patients were successfully managed for a unilateral femoral shaft fracture with an antegrade intramedullary nail by the same surgeon (RA). Time between hospital admission and surgery ranged from 24 to 48 hours. At one year follow-up, eight patients were identified with a femur malrotation more than $10^{\circ}$ in healed femur diaphyseal fracture. The Institutional Review Board approved the study and all patients were enrolled after a signed informed consent. Patients with bilateral fracture, pathological fracture, or articular fracture extension were excluded. A clinical exam excluded all patients with patellofemoral troubles or femur malrotation of the controlateral side in order to assess the controlateral patellofemoral joint. Minimum 12 months follow-up was required to assess the healing of the diaphyseal fracture without complications. Patient characteristics are reported in Table 1.

\subsection{CT-based patellofemoral assessment}

Both lower-limbs with healed fracture and controlateral side were evaluated from CTscan with $3 \mathrm{D}$ reconstructions according to the Symbios protocol (ref), from the femoral head center to the ankle joint, with 3-mm slices for articular assessment (General Electric Healthcare, Milwaukee, WI). The type and the importance of the femur malunion were evaluated from CT-based reconstructions in the 3 planes. Malrotation was defined between the femoral neck axis and the posterior bicondylar plane distally. A difference of more than $10^{\circ}$ between the healed and the healthy side was considered 
100 for the inclusion. An increased angle corresponded to an increased internal rotation of

101 the distal epiphysis of the femur. The patellofemoral assessment of the both sides was 102 performed using axial view and contained [11]:

103 - The lateral patellofemoral angle, defined by the angle between the lateral facet

104 of the patella and the tips of the femoral trochlea.

105 - The patellar tilt angle, defined by the angle between the axial axis of the patella 106 and the tips of the femoral trochlea.

107 - The bisect offset of the patella describe lateral patellar displacement.

108 - The congruence angle, a measure of lateral displacement and patellar tilt.

\section{$109 \quad 2.3$ Finite element modeling analysis}

110 2.3.1 Knee joint geometry:

111 A 3D model of the knee joint was developed using MRI from healthy knee at $30^{\circ}$ of

112 flexion (General Electric Healthcare, Milwaukee, WI). 3D reconstructions used Mimics

113 Software (Materialise HQ, Leuven, Belgium) and bone and cartilage segmentation was

114 performed using MRI reconstructions in the three planes. Then, bone and cartilage 115 surface meshes were generated using a software package (3-Matic, Materialise $\mathrm{HQ}$,

116 Leuven, Belgium) with a surface mesh for bones and tetrahedral volume mesh for 117 cartilage. The cartilage then received a finer and more precise mesh size in the open 118 source mesh generator GMSH software. 
121 Material properties were defined from surfaces meshes using ABAQUS (v6.4, Hibbitt,

122 Karlsson \& Sorensen, Inc., Pawtucket, RI, USA) and based on literature data. The 123 femur bone, tibia bone, patella were modelised as rigid bodies. The joint surfaces of 124 the femur and patella are attached to the bones by a "coupling" stress with the 125 reference points of the rigid surfaces. Thecartilage is idealized as homogeneous, 126 isotropic and linearly elastic. For cartilage, we used a Young's modulus of $5 \mathrm{MPa}$ and 127 a Poisson's Ratio of 0.47 . The cartilage density was of $1 \mathrm{~g}^{\mathrm{cm}} \mathrm{cm}^{-3}$. The interaction 128 between the 2 cartilages is surface/surface type with a friction coefficient of 0.02 . The 129 patellar tendon is modelled by a spring fixed between the patella and the tibial 130 tuberosity with a stiffness of $2000 \mathrm{~N} / \mathrm{mm} \cdot 2.3 .3$ Load and constraints:

131 A vertical compression force of $276 \mathrm{~N}$ was applied parallel to the femur axis on the 132 patellar tendon. Then, the rotational position of the femoral epiphysis (3D femoral bone 133 and cartilage) was generated from 1 to 10 degrees through the femoral anatomical 134 axis to simulate femoral malrotation. The finite element analysis was performed at 30 135 degrees of knee flexion and our region of interest (ROI) was the cartilage surface of 136 the patella.

\section{$137 \quad 2.4$ Statistical analysis}

138 Statistical analysis was performed using statistical software (XLSTAT, Addinsoft, NY, 139 USA). A normality test was used by the Shapiro-Wilk method. Non-parametric tests 140 and student $t$ test were used for analyzing variables.

\section{RESULTS}

\section{$142 \quad 3.1$ Patellar position and joint congruency}


143 We found a significant difference for the lateral patellofemoral angle and the 144 congruence angle, with $p$ value of 0.013 and 0.022 respectively. Comparison values in 145 CT-based PF assessment are shown in Table 2.

\subsection{Finite element modelling analysis}

148 Because of limitation in the experimental process as contact adjustment, data analysis 149 could not be performed beyond $10^{\circ}$ of external rotation and $5^{\circ}$ of internal rotation. The Von Mises stress variation was reported according to the value of the malrotation angle

151 (Fig.1) and to the geometry of the patellar surface (Fig.2). The mean load curve 152 increased with the malrotation angle, regardless the type of rotation (Fig.1). We found 153 a high coefficient of determination $\left(R^{2}\right)$ for internal rotation $\left(R^{2}=0.95\right)$ and for external 154 rotation $\left(\mathrm{R}^{2}=0.96\right)$. From the Fig.1, a linear force relationship to approximate the 155 average stress (VMs) regarding to femur malrotation (Mr) could be established:

For internal rotation: $\mathrm{VMs}=0,1807(\mathrm{Mr})+0,8093$

For external rotation: $\mathrm{VMs}=0,0681(\mathrm{Mr})+0,7407$

158 The average Von Mises stress was $1.608 \mathrm{MPa}$ for $5^{\circ}$ internal rotation, especially on 159 the lateral facet. The average stress was $1.39 \mathrm{MPa}$ for $10^{\circ}$ external rotation, especially 160 on the medial facet.

\section{DISCUSSION}

Femoral malrotation is a well-known cause of PF symptoms following 164 diaphyseal fracture, due to changes in PF kinematic and patellar stress. The aim of 165 this study was to determine the role of femoral malrotation in the distribution of loading 166 variations in the PF joint. [2]. 
167 Several studies dealed with the correlation between femur malrotation and patellar 168 alignment following femur diaphyseal fracture. The results of our study revealed 169 changes in PF conformity and patellar position regarding to the healthy side. We 170 reported that femur malrotation $>10^{\circ}$ was associated to an increase in patellar tilt and 171 congruence angle. Yildirim et al. reported the effect of femoral deformity following 172 femoral shaft fracture, underlying the role of external malrotation $>10^{\circ}$ [6]. They 173 observed deterioration in the PF scores and medial patellar tilt for patient with such 174 deformities. When clinical series used to associate rotational deformities $<15^{\circ}$ are 175 generally related to fewer clinical symptoms, we highlighted that femur malrotation > $17610^{\circ}$ jeopardized PF alignment.

177 We emphasized an increased stress distribution in case of femur malrotation. To our 178 knowledge, this is the first study reporting linear distribution in patellar stress with 179 gradual femoral deformity increment. The variation in PF stress distribution is widely published in literature, showing increased stress value and increased stress area 181 during knee flexion. Our study supports the fact that the rotation in distal femur seemed 182 to be also responsible for increasing PF stress. Our results support Liao et al. series 183 reporting higher patella cartilage stresses on the lateral facet of the patella after $5^{\circ}$ and $18410^{\circ}$ of femoral rotation. [12]. Thus, Lee et al. reported changes in kinematic of the PF 185 joint with increased quadriceps muscle strain and increased pressure over the patellar 186 facet at the contralateral side of the rotational deformity [13]. Our results are in 187 accordance with this conclusion, reporting a geometrical effect in external and internal 188 malrotation.

189 PF changes in axial alignment are clinically relevant, especially for anterior knee pain 190 and patellar instability $[4,6,12]$. However, the influence of stress distribution in anterior 191 pain is controversial, because of the participation of the involved biological factors. In 
192

193

194

195

196

197

198

199

200

201

202

203

204

205

206

207

208

209

210

211

212

213

214

215

a study of Besier et al., the role of cartilage stress in PF pain was analyzed based on patellar stress peak during stair climbing [14]. The authors highlighted that femur rotation was responsive for patellofemoral pain syndrom in females and limits in some functional activities, as running, jumping, stepping and squatting. These results are supported by increased patella cartilage stress, mean hydrostatic pressure and shear stress when the femur was internally rotated $5^{\circ}$ and $10^{\circ}$ [12]. Souza et al. emphasized the effect of femur rotation was more clinically relevant from $45^{\circ}$ to knee extension [15]. Yildirim et al. reported a decrease in the mean patella score due to external malrotation beyond $10^{\circ}[6]$. External rotation appeared to be more tolerate than internal rotation, especially because of foot compensation and ability to correct limb rotational alignment [2].

Our study had limits. We limited our FEM analysis to $5^{\circ}$ internal rotation and $10^{\circ}$ external rotation at $30^{\circ}$ knee flexion. However, the influence of femoral version seemed to be the more pronounced in the first degrees of flexion and this range of flexion is clinically relevant for patellar engagement and PF symptoms $[12,15]$. The notion is supported by the results of Liao et al., with a higher lateral pressure at $45^{\circ}$ of knee flexion compared with pressure at $15^{\circ}[12]$. Secondly, we don't add loading apparatus and quadriceps morphology to the model, as Liao et al. did [12]. However, this modelization is mostly useful in case of variation in knee flexion by changes in quadriceps muscle forces, while we used only one position of knee flexion.

\section{CONCLUSION}

Femur malrotation is a cause of patellar symptoms following diaphyseal fracture treated by intramedullary nailing. Our study reported changes in patellar position and patellar stress. Malrotation in internal and external rotation could induce patellofemoral 
216 pain syndrome from smaller rotation than ten degrees. Care should be taken for

217 internal malrotation in the management of femoral shaft fracture due to relationship

218 between malrotation and patellar stress even in internal rotation.

220 Conflict of Interest: The authors declare that they have no conflict of interest with the

221 submitted work. JNA reported consultancy from Zimmer Biomet and royalties from

222 Zimmer Biomet and Symbios outside the submitted work.

223 Funding: There is no funding source.

224 Ethical approval: This article contain study with human participants (approval by CNIL

225 French data protection agency (CIL-APHM-03-06-2014))

226 Informed consent: Informed consent was obtained from all individual participants 227 included in the study. 


\section{REFERENCES}

230

231 [1] Daglar B, Gungor E, Delialioglu OM, Karakus D, Ersoz M, Tasbas BA, et al. Comparison of knee function after antegrade and retrograde intramedullary nailing for diaphyseal femoral fractures: results of isokinetic evaluation. J Orthop Trauma 2009;23:640-4.

[2] Gugala Z, Qaisi YT, Hipp JA, Lindsey RW. Long-term functional implications of the iatrogenic rotational malalignment of healed diaphyseal femur fractures following intramedullary nailing.

Clin

Biomech 2011;26:274-7. doi:10.1016/j.clinbiomech.2010.11.005.

[3] Helmy N, Jando VT, Lu T, Chan H, O’Brien PJ. Muscle function and functional outcome following standard antegrade reamed intramedullary nailing of isolated femoral shaft fractures. J Orthop Trauma 2008;22:10-5.

[4] Karaman O, Ayhan E, Kesmezacar H, Seker A, Unlu MC, Aydingoz O. Rotational malalignment after closed intramedullary nailing of femoral shaft fractures and its influence on daily life. Eur J Orthop Surg Traumatol 2014;24:1243-7. doi:10.1007/s00590-013-1289-8.

[5] Sennerich T, Sutter P, Ritter G, Zapf S. Computerized tomography follow-up of the ante-torsion angle after femoral shaft fractures in the adult. Unfallchirurg 1992;95:301-5.

[6] Yildirim AO, Aksahin E, Sakman B, Kati YA, Akti S, Dogan O, et al. The effect of rotational deformity on patellofemoral parameters following the treatment of femoral shaft fracture. Arch Orthop Trauma Surg 2013;133:641-8. doi:10.1007/s00402-013-1705-X. 
[7] Patel NM, Yoon RS, Cantlon MB, Koerner JD, Donegan DJ, Liporace FA. Intramedullary nailing of diaphyseal femur fractures secondary to gunshot wounds: predictors of postoperative malrotation. J Orthop Trauma 2014;28:711-4.

[8] Kessler 0, Patil S, Colwell CW, D’Lima DD. The effect of femoral component malrotation on patellar biomechanics. J Biomech 2008;41:3332-9. doi:10.1016/j.jbiomech.2008.09.032.

[9] Valkering KP, Breugem SJ, van den Bekerom MP, Tuinebreijer WE, van Geenen RCI. Effect of rotational alignment on outcome of total knee arthroplasty. Acta Orthop 2015;86:432-9. doi:10.3109/17453674.2015.1022438.

[10] Verlinden C, Uvin P, Labey L, Luyckx JP, Bellemans J, Vandenneucker H. The influence of malrotation of the femoral component in total knee replacement on the mechanics of patellofemoral contact during gait AN IN VITRO BIOMECHANICAL STUDY. J Bone Joint Surg Br 2010;92:737-42.

[11] Bull A, Katchburian M, Shih Y-F, Amis A. Standardisation of the description of patellofemoral motion and comparison between different techniques. Knee Surg Sports Traumatol Arthrosc 2002;10:184-93. doi:10.1007/s00167-001-0276-5.

[12] Liao T-C, Yang N, Ho K-Y, Farrokhi S, Powers CM. Femur Rotation Increases Patella Cartilage Stress in Females with Patellofemoral Pain: Med Sci Sports Exerc 2015;47:1775-80. doi:10.1249/MSS.0000000000000617.

[13] Lee TQ, Morris G, Csintalan RP. The influence of tibial and femoral rotation on patellofemoral contact area and pressure. J Orthop Sports Phys Ther 2003;33:68693.

[14] Besier TF, Pal S, Draper CE, Fredericson M, Gold GE, Delp SL, et al. The Role of Cartilage Stress in Patellofemoral Pain: Med Sci Sports Exerc 2015;47:2416-22. doi:10.1249/MSS.0000000000000685. 
278 [15] Souza RB, Draper CE, Fredericson M, Powers CM. Femur Rotation and Patellofemoral Joint Kinematics: A Weight-Bearing Magnetic Resonance Imaging Analysis. J Orthop Sports Phys Ther 2010;40:277-85. doi:10.2519/jospt.2010.3215.

281

282

283

284 


\section{TABLES}

Table 1 : Demographic characteristics

Table 2: Patellofemoral assessment from CT-based measurements in the cases series

\section{FIGURES}

Figure 1: Subject specific parameters used to create finite element model of the patellofemoral joint: segmentation at $30^{\circ}$ of flexion from High-resolution MRI (A), joint geometry modelling (B), bone and cartilage meshes (C), finite element model (D).

Figure 2: Average Von Mises stress regarding to the femoral malrotation (internal and external) with coefficient of determination (R2) and linear force relationship.

Figure 3: Von Mises stress distribution on the patellar cartilage at $30^{\circ}$ of flexion regarding to femoral malrotation. 